\section{Publication of abstracts presented at anaesthesia meetings}

To determine the publication rate of abstracts as peer-reviewed manuscripts during the five years subsequent to their presentation, the rates of publication of abstracts that were presented at meetings of four anaesthesia societies (American Society of Anesthesiologists (ASA), International Anesthesia Research Society (IARS), Anaesthesia Research Society (ARS) and Canadian Anaesthetists' Society (CAS), in 1985 were determined. Abstracts (total $=215)$ from each of the four meetings were selected (ASA $n=114 / 573$ total, IARS $n=39 / 119$, ARS $n$ $=33 / 99$ and $C A S n=29 / 58)$ and their appearances in the literature as peer-reviewed manuscripts were determined using MEDLINE for the years 1985 to 1990 under the surname of the presenting author. The contents of the abstracts were compared with those of the resultant manuscripts. The proportions of abstracts from each of the four societies that were published as manuscripts were compared. We found that the mean proportion of abstracts from all four societies that were published as manuscripts within three years of presentation was $44 \%$ and within five years $50 \%$. The proportions of abstracts that were published as manuscripts from the four societies were similar. Of the abstracts that were published as manuscripts, $13 \%$ from the ASA, $16 \%$ from the IARS, $16 \%$ from the ARS and $0 \%$ from the CAS were published four or five years afier abstract presentation. Although the overall proportion of abstracts that was published within five years of presentation did not differ from the rate of publication within three years, we recommend that a uniform policy with respect to the time interval for citation of abstracts be adopted for all anaesthesia journals.

Dans le but de déterminer le pourcentage des abstracts qui atteignent le stade de publication sous forme d'articles, nous

Key words

PUBLICATIONS.

From the Department of Anaesthesia and the Research Institute, The Hospital for Sick Children, University of Toronto, Toronto, Ontario, Canada. Presented in part at the American Society of Anesthesiologists Annual Meeting, San Francisco, 1991.

Address correspondence to: Dr. J. Lerman, Department of Anaesthesia, The Hospital for Sick Children, 555 University

Ave., Toronto, Ontario, M5G 1 X8 Canada.

Accepted for publication 29th March, 1993.
S.M. Yentis FCAnaes, F.A. Campbell FCAnaes, J. Lerman BASc MD FRCPC avons fait un relevé d'abstracts présentés en 1985 à quatre sociétés d'anesthésistes. Ces abstracts avaient fait l'objet d'une présentation aux réunions de ces sociétés en 1985 et avaient été acceptés ultérieurement comme articles après révision par des comités de lecture. Les sociètés sont l'American Society of Anesthesiologists (ASA), L'International Anesthesia Research Society, l'Anaesthesia Research Society (ARS) et la Société Canadienne des Anesthésistes (SCA). Des abstracts (total $=215)$ provenant de chacune des quatre réunions ont été choisis $(A S A n=114 / 573$, IARS $n=39 / 119$, ARS $n=$ $33 / 99$ et $S C A n=29 / 58)$. Leur apparition dans la littérature a été retracée dans le MEDLINE sous le nom de l'auteur principal pendant les années 1985-1990. Le contenu des abstracts a été comparé à celui des l'articles. La proportion des abstracts donnant naissance à des articles a été comparée pour chacune des sociétés. Pour les quatre sociétés, nous avons trouvé que la proportion moyenne de publications en-deça de trois ans de la présentation a été de $44 \%$ et de cinq ans de $50 \%$. Cette proportion est la même pour les quatre sociétés. De l'ASA, 13\%, de l'IARS, 16\%, de l'ARS, $16 \%$ et de la SCA, 0\% des abstracts ont produit à des articles après quatre ou cinq ans de leur présentation. Bien que la proportion générale des abstracts publiés en-deça de cinq ans de leur présentation ne soit pas différente de la proportion trouvée après trois ans, nous recommandons qu'une politique uniforme soit adoptée par toutes les revues d'anesthésie sur la limite de temps au cours de laquelle on peut utiliser un abstract comme référence.

Some journals limit the citation of abstracts as references to a specified time after publication of the abstract in an indexed journal, e.g., three years for Anesthesiology and five years for Anesthesia and Analgesia. Other journals such as British Journal of Anaesthesia and Canadian Journal of Anaesthesia* do not have a limit on the citation of abstracts. When the time to publication of a complete manuscript exceeds the limits set by the journal, the respective abstracts can only be cited as footnotes, even though the data therein may be relevant.

In a study of the publication rate of abstracts that were presented at two meetings of the International Anes-

*The Canadian Journal of Anaesthesia has an informal limit of five years - Editor-in-Chief. 
thesia Research Society (IARS) and one meeting of the American Society of Anesthesiologists (ASA) during the period 1978-1980, 30-44\% of the abstracts presented were published as peer-reviewed manuscripts within 1-2 years of presentation. ${ }^{1}$ However, the publication beyond this time was not assessed even though abstracts could be cited for only three or five years after presentation in some journals.

The aim of this study was to determine and compare the proportions of abstracts presented at four anaesthesia meetings in 1985 that were subsequently published as peer-reviewed manuscripts within three and five years of presentation to determine whether the temporal limit on the citation of abstracts is reasonable.

\section{Methods}

Abstracts (both oral and poster presentations) presented at the 1985 meetings of the following four societies: American Society of Anesthesiologists (ASA), International Anesthesia Research Society (IARS), Anaesthetic Research Society (ARS) and Canadian Anaesthetists' Society (CAS) were reviewed. The abstracts were published in the following journals: ASA - Anesthesiology, IARS - Anesthesia and Analgesia, ARS - British Journal of Anaesthesia, CAS - Canadian Anaesthetists' Society Journal. The North American societies (ASA, IARS and CAS) each held one meeting in 1985, whereas the ARS held three. In the case of ARS meetings, the abstracts from all three meetings were pooled and treated as one for the purpose of this study. A proportion of the abstracts that appeared in the respective journals of these meetings (total of 215) were surveyed: Anesthesiology, every fifth abstract (114/573); Anesthesia and Analgesia (39/119) and British Journal of Anaesthesia (33/99), every third abstract; and Canadian Anaesthetists' Society Journal $(29 / 58)$ every second abstract. The different frequency of abstract selection was designed to yield a similar proportion of the total abstracts presented at the respective meeting for review. The surname of the first author of each abstract was searched using MEDLINE for the years 1985-1990. If the surname of the first author on the abstract appeared anywhere in the list of authors of the peer-reviewed manuscript, the contents of the published manuscript were compared with the abstract.

The proportions of abstracts published as peerreviewed manuscripts were compared among societies using Chi-square analysis. $P<0.05$ was accepted as statistically significant.

\section{Results}

The total number (proportion) of abstracts that were subsequently published as peer-reviewed manuscripts within three years of presentation was $44 \%$ whereas that for pub-

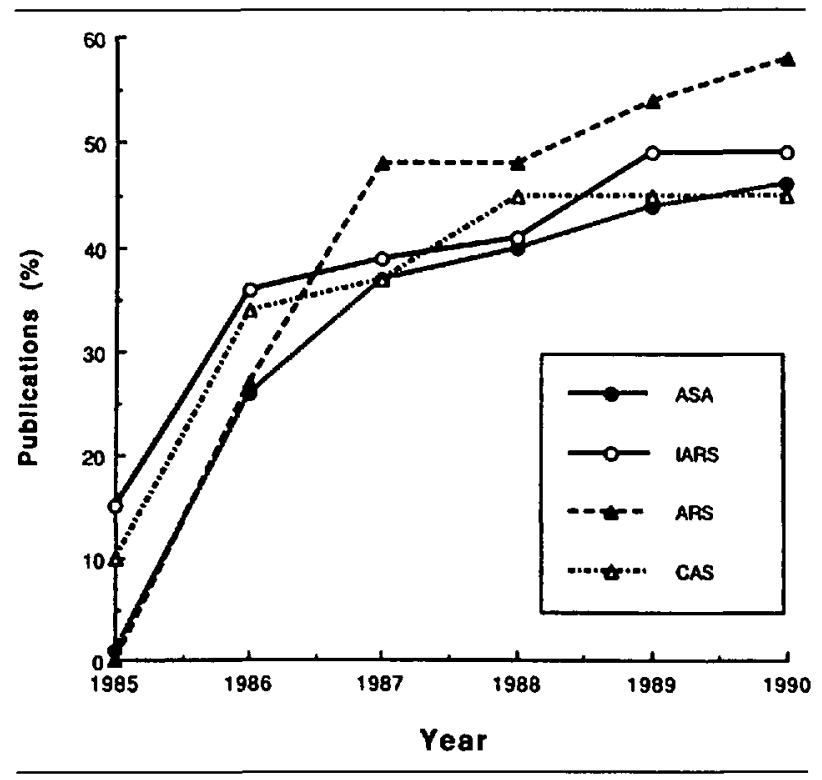

FIGURE Cumulative proportions of a random selection of abstracts published as peer-reviewed manuscripts within five years of presentation at four anaesthesia meetings.

lication within five years was 50\% (Figure). Of those abstracts that were subsequently published as manuscripts, $88 \%$ were published in less than three years. However, $13 \%$ of the ASA abstracts and $16 \%$ of the IARS and ARS abstracts were not published until four or five years after presentation. All of the abstracts published from the CAS were published within three years. The proportions of abstracts that were published as peer-reviewed manuscripts did not differ among the four societies at any time (Figure).

\section{Discussion}

Of the abstracts that were successfully published as peerreviewed manuscripts within five years, $44 \%$ were published within three years and $50 \%$ within five years. Of the abstracts that were published as manuscripts, up to $16 \%$ were not published until four or five years after abstract presentation. Those abstracts that were not published until four or five years after presentation could not be cited by authors of manuscripts submitted to Anesthesiology during the last two years before publication. Such a limitation might restrict the scientific data included in some anaesthesia manuscripts during this period.

It is possible that we underestimated the true publication rate of abstracts as peer-reviewed manuscripts. Several plausible sources for this underestimation include: (1) the author who presented the abstract was not a coauthor on the final manuscript, (2) the manuscript was published in a non-indexed journal and (3) the manuscript was published more than five years after presen- 
tation of the abstract. These would have resulted in a loss of the abstract to follow-up and the erroneous conclusion that the manuscript was never published. To address the third source of underestimation, a follow-up study of up to ten years after presentation of an abstract may be indicated. It seems reasonable that all three sources of error affected the likelihood of publication of abstracts from the four meetings similarly.

The overall publication rates in this study are consistent with those of Meranze et al. ${ }^{1}$ despite a $77 \%$ increase in the number of abstracts presented at the ASA and a $100 \%$ increase in those presented at the IARS in 1985 compared with 1982. As the number of abstracts accepted for presentation at these meetings increases, one might expect the proportion of abstracts that are subsequently published as manuscripts also to increase. Whether the increase in the number of anaesthesia journals can continue to accommodate the increasing numbers of manuscripts remains to be determined. Moreover, whether the proportion of abstracts that are subsequently published as manuscripts should indeed be $50 \%$, or greater or less, depends on the perceived role of abstracts and abstract presentations at scientific meetings.

Abstracts presented at the four meetings were equally likely to result in publication of peer-reviewed manuscripts. We are unable to comment on possible differences in the acceptance criteria of the meetings for the abstracts or of the journals for the manuscripts.

In conclusion, $44 \%$ of abstracts presented at anaesthesia meetings in 1985 were published as peer-reviewed manuscripts within three years of presentation and 50\% within five years. However, of the total number of abstracts published within five years of presentation as abstracts, as many as $16 \%$ did not appear as peer-reviewed manuscripts until four or five years after presentation.

\section{Reference}

1 Meranze MS, Ellison N, Greenhow DE. Publications resulting from anaesthesia meeting abstracts. Anesth Analg 1982; 61: 445-8. 